\title{
The Application Research of PBL and LBL in English Teaching in Medical Colleges
}

\author{
Xiangfa Zeng ${ }^{1, a}$, Song Wang ${ }^{2, b}$ * \\ ${ }^{1}$ Chengdu Medical College, Chengdu, Sichuan, China \\ $2{ }^{*}$ Corresponding Author, Chengdu Medical College, Chengdu, Sichuan, China \\ a1362806408@qq.com, ${ }^{b}$ wsong80@126.com
}

Keywords: Medical students; PBL and LBL English Teaching

\begin{abstract}
Objective: To quantitatively study the effectiveness of the combination teaching mode of PBL and LBL on improving teaching quality. Methods: The combined teaching mode of PBL and LBL in English teaching was applied in the experimental class. The traditional LBL teaching model was adopted for the control class that the same teacher teaches with the same teaching materials and the same teaching hours. After the experiment, the students in the experimental class were surveyed and the SPSS 22.0 statistical software package was used for data analysis. The English levels of the students in the control class and experimental class before and after the experiment were measured and analyzed. Results: Statistical analysis found that there was a statistically significant difference $(\mathrm{P} \leq 0.05)$ in the post-test between the experimental class students and the control class students who did not have statistical differences $(\mathrm{P} \geq 0.05)$ in the pretest. In the experimental class, the recognition degree of the teaching mode of PBL and LBL in combination with English teaching was $3.96 \pm$ 0.517, the English learning interest score was $4.07 \pm 0.587$, the English learning attitude score was $3.63 \pm 0.524$, and the English learning effect score was $4.19 \pm 0.261$. Conclusion: Most students prefer the combination of PBL and LBL, which can greatly improve students' English proficiency, stimulate students' interest in learning English, and improve students' oral English, listening ability, and the ability to collect and collate the learning materials.
\end{abstract}

\section{Introduction}

As the Internet+ enters into people's life, work, and study, the reform of English teaching in colleges and universities is further developed. College English makes full use of multimedia and network technology, adopts a new teaching model, and develops towards the orientation of student-centered personalized learning and self-directed learning. One of the purposes of English courses in medical colleges is to cultivate students' practical ability in using English, so that medical students can use English in scientific research, medical treatment, teaching and related activities in their future work. It is essential for medical students to update medical knowledge, to write medical English papers, to attend international conferences, to understand foreign experts' lectures (Jun sheng Li, Li Li et al. 2007).

The LBL teaching method is teacher-centered, focusing on lectures, adopting the entire class to inculcate teaching, guaranteeing the systematic and logical knowledge transfer, and possessing incomparable advantages in other teaching methods (Barrow H.S 1986). However, the LBL teaching method has little effect on promoting students' application of knowledge. In 1969, Professor Barrows, an American professor of neurology, founded the PBL model based on constructivism at Medical School of McMurst University in Canada, and implemented a group-teaching method combining self-study with teacher guidance. PBL emphasizes setting learning to complex and meaningful problem situations. Learners work together to solve real problems, learn the scientific knowledge underlying the problem, and gain problem-solving skills and the ability to learn independently (Hmelo, C.E.,\& Ferrari,M 1997). The PBL teaching model is grounded on cultivating students' flexible knowledge base, developing high-level thinking ability, independent learning ability and cooperation ability, which has been widely used in medical 
education (Meiling Jiang 2007). In 1986, Xi'an Jiaotong University Health Science Center and Shanghai Jiao Tong University School of Medicine took the lead in introducing the PBL teaching method, which created a precedent for the PBL teaching method in China. It was widely applied in other specialized fields other than the medical specialty of domestic universities and has witnessed good results.

In recent years, some experts and scholars have begun to do the research of the application of PBL in college English teaching. The scholars introduced the basic characteristics and process of PBL, the potential and feasibility of using PBL to cultivate innovative foreign language talents, the problems and difficulties in the PBL application of foreign language education in China, and its corresponding solutions (Peiya Gu 2007; Yongbi Zhi 2009). Another research is based on the characteristics of the PBL teaching model, using the computer network as a cognitive tool to carry out curriculum reforms in college oral classes to improve students' oral English (Zhichen Wang 2011). The inevitability, advantages, problems and challenges of developing PBL teaching in medical colleges and universities are discussed (Hong Zhang 2014). However, most of these studies use the PBL teaching method to test and discuss its superiority. They ignored the importance of the LBL teaching model in guaranteeing the logicality and systematicness of knowledge transfer. The discussions of PBL are mostly limited to qualitative discussion. In the research, PBL and LBL teachings are organically combined to exert their respective advantages to improve the quality of teaching, so as to improve medical students' interest in English learning and improve their ability to listen, speak, read, write, and translate in English.

\section{Research Objects and Methods}

The objects of study are the 2nd class and 6th class of the 2017 Clinical Medicine in our school. The two classes have the same number of students. The same teacher used the same teaching materials to teach them within the same hours. The Clinical Medicine Class 2 is the experimental class. Based on the principle of heterogeneous grouping, according to the differences in student gender, personality, grades, learning ability, and behavioral habits, students were divided into groups of 6 students by the principle of "intragroup heterogeneity, group homogeneity" (Meiling Jiang 2003). PBL and LBL were combined in the teaching process to allow students to study each unit in advance. In the classroom, the content of the text was discussed in groups. Based on the text content, students asked questions. The teacher and the students discussed together and determined the solution for discussion. After the class, the students prepared for the agreed questions and presented the results in the next class through PPT, speeches, and other forms. The teacher then supplemented the problems and teaching content in student learning. Finally, teachers evaluated students' achievements. At the end of the entire teaching period, the students were given questionnaires evaluating the teaching effects of the combination of PBL and LBL teaching methods, and SPSS 22.0 software was applied to statistically analyze the data.

The questionnaire was revised based on the questionnaire designed by Miu Zhangyan (Miu Zhangyan 2014). A total of 22 questions were asked to investigate the degree of acceptance of PBL and LBL in the experimental group, as well as English learning attitude, learning motivation, learning effectiveness, cooperative learning, and autonomous learning. Each question used Likert five-grade scale with respectively five responses "strongly agree”, "agree”, "not necessarily", "disagree", and "very disagree". They are recorded respectively 5, 4, 3, 2, 1 point. A total of 41 questionnaires were issued and 40 valid questionnaires were recovered with $97.56 \%$ recovery rate.

\section{Research Results}

\subsection{The comparison of the English level between the experimental group and the control group}

Before the experiment, students in the control group and experimental group participated in the pretest of English proficiency. The test paper of March 2017 National English Test Grade 2 was 
used to test the English proficiency of the two classes. After one-year teaching experiment, the test paper of the National English Test Grade 3 in September 2017 was used to measure the English level of the two classes. The objective questions of the two tests were done through the scoring machine. The subjective questions were averaged by the two members of the research group after reviewing to reduce the influence of human factors on the English level of the subjects. The analysis of pretest results reflected that there was no significant difference in English level before the experiment between the two groups ( $\mathrm{P} \geq 0.05)$. Post-test analysis shows that after the experiment, the English score of the experimental group is better than that of the control group. There was a statistically significant difference in English level between the two groups $(\mathrm{P} \leq 0.05)$.

\subsection{Medical students’ English learning motivation}

The questionnaire shows that $85.6 \%$ of medical students study English in order to publish research papers. $72.8 \%$ of them study English to find a better job, 63.7\% of them study English due to language love. 62.4\% study English for international academic exchanges. $40.3 \%$ are for the country future. $38.2 \%$ are for the master's entrance examination. 35.2\% study English to obtain higher scores. 32.1\% learn to go abroad. $20.6 \%$ do it for graduating. Only $8.3 \%$ study English for the family happiness (Figure 1).

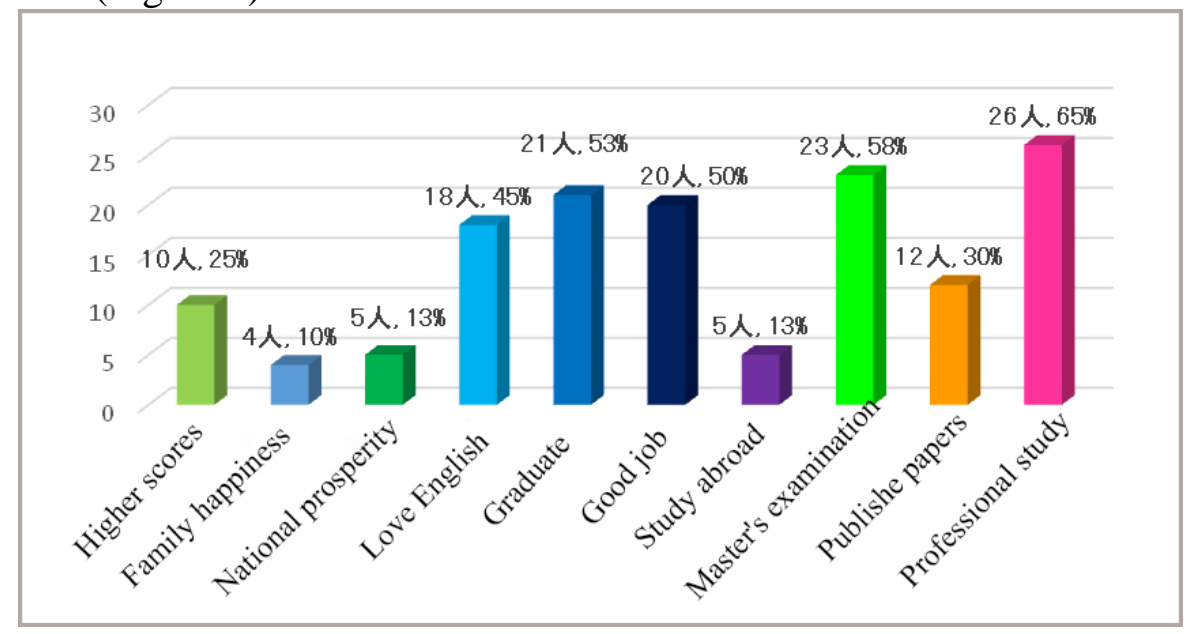

Figure 1 Student's English Learning Motivation

\subsection{Medical students' recognition of the combination teaching mode of PBL and LBL}

The recognition of the combination teaching mode of PBL and LBL in the experimental group was shown in Table 1. It can be seen from Table 1 that the overall average score of students in the combination teaching model of PBL and LBL is $3.96 \pm 0.517$, which is close to 4 points. In particular, students believe that cooperative learning in the combination teaching mode is very important (Question 4) with the average score of 4.49. Medical students are very much in agreement with the combination of PBL and LBL.

Table 1 Statistics of the combination teaching mode of PBL and LBL for medical students

\begin{tabular}{cccccc}
\hline Category & Question Item & The Lowest Point & The Highest Point & Mean & The Standard Deviation \\
\hline Teaching & 4 & 3 & 5 & 4.49 & 0.553 \\
Method & 6 & 3 & 5 & 3.73 & 0.742 \\
Recognition & 7 & 2 & 5 & 3.66 & 0.794 \\
\hline Total (average) & 3 & 2.67 & 5 & 3.96 & 0.517 \\
\hline
\end{tabular}

\subsection{An investigation of the interest and attitude of medical students in English learning}

In the combined teaching mode of PBL and LBL, the survey of medical students' interest in learning English is shown in Table 2. Medical students' attitude to English learning is shown in Table 3. Table 2 shows that medical students have strong interest in learning English after the 
combination of PBL and LBL. The average score of related items in English study interest reaches 4.07 \pm 0.587 . Many of them want to learn English well (Question 13), with an average score of 4.66. And medical students want to speak English as much as possible (Question 8), with an average score of 4.29. They also have strong desire to learn English (Question 17) with an average score of 4.15 .

Table 2 Medical Students' English Learning Interest Statistics

\begin{tabular}{cccccc}
\hline Category & Question Item & The Lowest Point & The Highest Point & Mean & The Standard Deviation \\
\hline \multirow{5}{*}{$\begin{array}{c}\text { Study } \\
\text { Interest }\end{array}$} & 2 & 2 & 5 & 3.56 & 0.776 \\
& 11 & 1 & 5 & 4.29 & 1.066 \\
& 12 & 1 & 5 & 3.95 & 0.999 \\
& 13 & 2 & 5 & 3.80 & 0.782 \\
\hline Total (average) & 17 & 5 & 5 & 4.66 & 0.617 \\
\hline
\end{tabular}

Table 3 shows that the medical students' attitude towards English learning is relatively positive after the combination of PBL and LBL, and the average score of related items is $3.63 \pm 0.524$. Many students try to understand English as much as possible (Question 10). However, medical students spend less time learning English (Question 16), with an average score of 3.10.

Table 3 Medical Students' English Learning Attitude Statistics

\begin{tabular}{cccccc}
\hline Category & Question Item & The Lowest Point & The Highest Point & Mean & The Standard Deviation \\
\hline & 3 & 2 & 5 & 3.51 & 0.746 \\
Study & 5 & 2 & 5 & 3.54 & 0.840 \\
Attitude & 9 & 1 & 5 & 5.73 & 4.001 \\
& 10 & 2 & 5 & 3.90 & 0.894 \\
& 14 & 2 & 5 & 3.10 & 0.768 \\
\hline total & 16 & 1 & 5 & 3.63 & 0.524 \\
\hline
\end{tabular}

\subsection{Investigations of medical students' English learning effect}

After the combination of PBL and LBL teaching model, the medical students' learning effect was relatively satisfactory. The average score of related items is $4.19 \pm 0.261$ (Table 4). While the medical students are more confident of themselves, and they can perform the ability cultivated by the combination teaching mode of PBL and LBL to collect and organize the relevant information (question 21 and 22), which are 4.37 and 4.22 respectively. At the same time, medical students believe that the collection and arrangement of information in learning stimulated their interest in English learning (Question 19), with a score of 4.20. However, when the teacher asked questions, the medical students were not confident enough to answer questions (Question 15) with the score of 4.07, which was the lowest score of the six surveyed items. 
Table 4 Statistics of medical students' English learning effects

\begin{tabular}{cccccc}
\hline Category & Question Item & The Lowest Point & The Highest Point & Mean & The Standard Deviation \\
\hline \multirow{5}{*}{ Study } & 15 & 3 & 5 & 4.07 & 0.685 \\
Effects & 18 & 3 & 5 & 4.10 & 0.625 \\
& 19 & 3 & 5 & 4.20 & 0.601 \\
& 20 & 3 & 5 & 4.17 & 0.587 \\
& 21 & 3 & 5 & 4.22 & 0.525 \\
& 22 & 3 & 5 & 4.37 & 0.536 \\
\hline \multirow{2}{*}{ total } & 6 & 3 & 5 & 4.19 & 0.261 \\
\hline
\end{tabular}

\section{Discussion}

There are 10 main types of motivation for medical students to learn English: higher scores, family happiness, national prosperity, language love, successful graduation, good jobs, study abroad, master's entrance exams, papers publication, and professional courses. For medical students in non 985 or 211 general medical schools, professional courses, master's entrance examinations and successful graduation are the most urgent tasks they face. Many medical students in general medical colleges want to use English language as tools to study their professional courses, finally pass the master's entrance exam to pursue a master degree or an academic master degree to improve their competitiveness in employment and stand out from the fierce employment competition, or use their English language skills to be directly employed. For students from ordinary families, studying abroad is unrealistic. Learning English is not a family or a national reason.

The statistics in Table 1 reflect that most medical students like the teaching mode of PBL and LBL. This is mainly related to the characteristics of traditional college English teaching mode, PBL and LBL teaching mode. The majority of traditional college English in ordinary colleges and universities is indoctrination teaching with "teachers-centered”. Students' participation is not high, and medical students are disgusted with this traditional teaching method. The essence of the combination teaching mode of PBL and LBL lies in taking the problem as the center, giving full play to the guiding role of the problems in the learning process, mobilizing the initiative and enthusiasm of the students to participate in the process of learning, so as to improve their language application ability. Therefore, the statistical data in Table 2 reflects the high interest of medical students in learning English. The combination teaching mode of PBL and LBL further enhances the enthusiasm of medical students for learning English. Many students also recognize the importance of learning English well to their future work and research.

Although medical students have strong interest and motivation in learning English, due to the heavy learning tasks and students have not yet fully adapted to university life, the time invested in English learning is not enough (Table 3). Medical students have relatively low scores in English learning time (Question 16, score is 3.10). However, through the combination teaching mode of PBL and LBL, the problem is the main axis to make students play an important role in learning. Through various forms of group cooperative learning and self-directed learning, English topics report, drama performances, etc., to cultivate their knowledge of meta cognitive ability, the use of specific knowledge and communication skills, oral English expression ability, listening ability. And the ability to collect and collate data have been greatly improved (Table 4, scores of questions 18, 20, and 22 of the questionnaire are 4.10, 4.17, and 4.37, respectively). According to the theory of constructivism, learning is the process of constructing students' active meaning. Learners form, enrich, and adjust their cognitive structure through the interaction of new and old knowledge, experiences. And learning is a two-way process. On the one hand, learners incorporate new knowledge into existing cognitive structures and gain new meanings. On the other hand, the original knowledge experience is adjusted or reorganized because of the inclusion of new knowledge. The 
inquiry-based learning and cooperative learning based on the constructivism theory are fully integrated in the medical students' PBL and LBL teaching mode. The students participate and experience actively, and the English language ability is improved by the cooperation among the members of the group and the interaction between teachers and students. And also according to the language input hypothesis of the L2 acquisition expert Krashen and the language output hypothesis of the Merrill Swain, medical students consciously had a large number of English languages during the study process and the consulting of discussion materials of each textbook. In the process of group discussion and presentation of learning results, the English language is exported, and the scattered language knowledge is translated into their own integrated English language application ability.

However, medical students are not very confident in their participation in teaching activities (Table 4, questionnaire item 15, score 4.07). This is mainly due to the fact that medical students had a teacher-centered teaching model in secondary schools. Students had fewer opportunities to speak and few opportunities for oral practice. They still need to continue their efforts in their future English learning.

\section{Conclusion}

Through the field study of the combination teaching mode of PBL and LBL in experimental group and the traditional English teaching mode in control group, and the questionnaire survey on the experimental group, it was found that medical students prefer the combination teaching mode of PBL and LBL. Group cooperative learning and autonomous learning activities can improve medical students' oral English, listening ability, material collection and collation ability. Through the statistical analysis of the pretest and post-test for the experiment group and the control group, it was found that the English scores of the two classes were statistically different after the experiment, which proved that the combination teaching mode of PBL and LBL could improve the English learning effect and the language comprehensive utilization ability. The combination teaching mode of PBL and LBL is a good mode of College English teaching.

\section{Acknowledgement}

The work was supported by Sichuan Provincial Foreign Language Literature Research Center Fund (No.: SCWYH17-05).

\section{References}

[1] Barrow H.S. A Taxonomy of Problem-based Learning Methods [J]. Med Educ.1986, 20(6):481-48.

[2] Hmelo, C.E., \& Ferrari, M. The problem-based Leaning tutorial: Cultivating higher order thinking skills. Journal for the Education of the Gifted, 1997, 20(4):401-422.

[3] Peiya Gu. Theory and Practice of Multimedia Project Teaching Method [J]. Foreign language world, 2007, (02):2-8+31.

[4] Meiling Jiang. Problem-based learning: a useful teaching model [J]. Global education outlook, 2003, (03):62-66.

[5] Junsheng Li, Li Li, Wenhao Tang. Using Network Resources and Multimedia Technology to Improve Medical English Teaching [J]. Chinese Journal of Medical Education Research, 2007, (06):565-566.

[6] Zhangyan Miao. Problem-based approach (Application in College English teaching) [D].Anhui: Anhui University. 2014.

[7] Zhichen Wang, Hong Sun, Ying Liu. Using network resources to implement PBL teaching in 
College English listening and speaking classes [J]. Higher Education Forum, 2011, (04):46-48+62.

[8] Zhengang Yang. Application of PBL Method in Bilingual Teaching of Information Specialty Courses [J].Sun Yatsen University Forum, 2007, (09):145-147.

[9] Hongran Zhang, Suping Qin. Exploration of PBL English teaching mode in medical colleges and Universities [J]. Health Vocational Education, 2014, (04):46-48

[10] YongBi Zhi. The Application of PBL in Foreign Language Education in China: Significance, Dilemma and Outlet [J]. Foreign Language and Their Teaching, 2009, (07):33-37. 